\title{
Neural Simulation of Action: A Unifying Mechanism for Motor Cognition
}

\author{
Marc Jeannerod ${ }^{1}$ \\ Institut des Sciences Cognitives, 67 Boulevard Pinel, 69675 Bron, France
}

Received November 28, 2000

\begin{abstract}
Paradigms drawn from cognitive psychology have provided new insight into covert stages of action. These states include not only intending actions that will eventually be executed, but also imagining actions, recognizing tools, learning by observation, or even understanding the behavior of other people. Studies using techniques for mapping brain activity, probing cortical excitability, or measuring the activity of peripheral effectors in normal human subjects and in patients all provide evidence of a subliminal activation of the motor system during these cognitive states. The hypothesis that the motor system is part of a simulation network that is activated under a variety of conditions in relation to action, either self-intended or observed from other individuals, will be developed. The function of this process of simulation would be not only to shape the motor system in anticipation to execution, but also to provide the self with information on the feasibility and the meaning of potential actions.

( 2001 Academic Press
\end{abstract}

\section{INTRODUCTION: THE SIMULATION THEORY}

The possibility to experimentally access to cognitive or mental states characterized by absence of overt behavior represents a new avenue for neuroscience. In the field of human motor cognition, it is only recently that it was realized that actions involve a covert stage. This covert stage is a representation of the future, which includes the goal of the action, the means to reach it, and its consequences on the organism and the external world. Covert and overt stages thus represent a continuum, such that every overtly executed action implies the existence of a covert stage, whereas a covert action does not necessarily turns out into an overt action. The simulation theory to be developed in this paper postulates that covert actions are in fact actions, except for the fact that they are not executed. The theory therefore predicts a similarity, in neural terms, between the state where an action is simulated and the

\footnotetext{
${ }^{1}$ Address correspondence and reprint requests to author. E-mail: Jeannerod@isc.cnrs.fr.
}

state of execution of that action. The term $S$-states will be used throughout to designate those "mental" states which involve an action content and where brain activity can be shown to simulate that observed during the same, executed action.

\section{COVERT ACTIONS ARE NEURALLY SIMULATED ACTIONS}

The idea that certain cognitive states correspond to simulated actions is by no means new. These states now include a wealth of situations which correspond to covert actions (see Table 1). Some of them are accompanied by conscious experience, some are not. In spite of these differences, they all bear the same relationship to action, both at the behavioral and the neural levels. The main features of some of these states are outlined below.

\section{Imagined Actions}

Behavioral findings have accumulated in the past 10 years, showing that imagined actions retain the same temporal characteristics as the corresponding real action when it comes to execution (Decety et al., 1989). Similarly, temporal regularities which are observed in executed actions are retained in their covert counterparts. As an example, mental reciprocal tapping on targets of varying size follows the same constraints (e.g., Fitts law) as actual tapping on the same targets (Sirigu et al., 1995). This temporal similarity becomes even more obvious in non conscious operations, where the subject is simply requested to make an estimate about the feasibility of an action, for example to determine the feasibility of grasping an object placed at different orientations: the time to give the response is a function of the object's orientation, suggesting that the subject must mentally move his arm in an appropriate position before the response can be given. Indeed, the time to make this estimate is closely similar to the time taken to actually reach and grasp an object placed at the same orientation (Frak et al., 2001). Not surprisingly, motor imagery is one of the first situations for which it was specifically proposed that it should involve, in the subject's motor brain, neural 


\section{TABLE 1}

A Taxonomy of Behaviorally Defined S-States

\begin{tabular}{ll}
\hline \multicolumn{1}{c}{ Type of S-state } & Degree of awareness \\
\hline Intended action & Conscious/nonconscious \\
Imagined action & Conscious \\
Prospective action judgements & Nonconscious \\
Perceptually based decisions & Nonconscious \\
Observation of graspable objects & Nonconscious \\
Observation of actions performed & \\
$\quad$ by others & Conscious/nonconscious \\
Action in dreams & Conscious \\
\hline
\end{tabular}

mechanisms similar to those operating during the real action (see Jeannerod, 1994, 1997).

\section{Action Observation}

Another category of covert actions can be elicited by observation of actions performed by other individuals, as if the observer would use the implicit strategy of putting himself "in the shoes of the agent." At present, this concept, and its consequences on behavior, is taken as equivalent to "mind-reading," the ability for normal people to understand and predict the behavior of their conspecifics. One of the explanations proposed for mind-reading is that it represents an attempt to replicate and simulate the mental activity of the other agent. In other words, the observed action would activate, in the observer's brain, the same mechanisms that would be activated, were that action intended or imagined by the observer (Gallese and Goldman, 1998). Besides its "social" function, action observation also corresponds to simulating the "technical" content of the action, with the consequence of learning how to replicate it.

\section{NEUROPHYSIOLOGICAL VALIDATION OF THE SIMULATION THEORY}

Findings concerning neural activity during S-states, as measured by neuroimaging techniques, are summarized in Table 2. This table illustrates the fact that the activation networks, although they partially overlap, differ from one S-state to another, and also between covert and overt actions. This section will report results showing that, although there is a core network that pertains to all S-states, each S-state retains its own specific network.

\section{Motor System}

Activation of the motor system during S-states is a prerequisite for the simulation theory: this is what gives S-states their action content.

\section{Primary Motor Cortex}

fMRI studies unambiguously demonstrate that pixels activated during contraction of a group of muscles are also activated during imagery of a movement involving the same muscles (Roth et al., 1996). Porro et al. (1996) showed that pixels activated during both motor performance and motor imagery represent a large fraction of the whole population of pixels activated during motor performance (see also Lotze et al., 1999). Primary motor cortex activation reported during motor imagery amounts about $30 \%$ of the level observed during execution. It may not be found in all subjects (e.g., Gerardin et al., 2000). Similarly, during action observation, magnetoencephalography reveals a significant activation at the level of precentral motor cortex (Hari et al., 1998).

\section{TABLE 2}

Brain Areas Activated during S-States

\begin{tabular}{|c|c|c|c|c|c|}
\hline \multirow[b]{2}{*}{$\begin{array}{l}\text { Brain regions and Brodman areas } \\
\qquad(\mathrm{Ba})\end{array}$} & \multicolumn{5}{|c|}{ Conditions } \\
\hline & Execute & Intend & Imagine & $\begin{array}{l}\text { Observe } \\
\text { actions }\end{array}$ & $\begin{array}{c}\text { Observe } \\
\text { objects }\end{array}$ \\
\hline Precentral gyrus $\mathrm{Ba} 4$ & $4,8,10,12,13$ & & $9,10,13$ & 15 & \\
\hline Precentral gyrus (dorsal) Ba 6 & $1,8,10,14$ & & $4,8,9,10,14$ & 5,9 & \\
\hline Precentral gyrus (ventral) $\mathrm{Ba} 6$ & 1,14 & & 4,14 & 2,5 & 3 \\
\hline SMA (rostral) $\mathrm{Ba} 6$ & $6,10,13$ & & $8,9,10$ & 5,9 & \\
\hline Cingular gyrus $\mathrm{Ba} 24$ & $1,8,10,12,4$ & 7 & $4,8,10,14$ & & \\
\hline Superior frontal gyrus $\mathrm{Ba} 10$ & & & 4,8 & & \\
\hline Middle frontal gyrus $\mathrm{Ba} 9,46$ & & 7 & $4,8,9$ & 5 & \\
\hline Inferior frontal gyrus $\mathrm{Ba} 44,45$ & & & $4,8,9$ & $2,5,9,12$ & 11 \\
\hline Inferior parietal lobule $\mathrm{Ba} 40$ & $1,6,10,12,14$ & & $4,8,9,14$ & $2,5,9$ & 3 \\
\hline
\end{tabular}




\section{Corticospinal Pathway}

If motor cortex is active during S-states, its activity should influence the motoneuron level. This point was tested by directly measuring corticospinal excitability using transcranial magnetic stimulation (TMS) of motor cortex during both observed and imagined arm movements (Fadiga et al., 1995 and 1999, respectively). Motor evoked potentials (MEPs) were found to be increased, only in those muscles involved in the covert hand action. Accordingly, MEPs were selectively increased in a finger flexor when the subject mentally activated finger flexion, whereas MEPs in the antagonist extensor muscle remained unchanged. In addition, other types of imagery (e.g., visual) did not affect MEPs in any of the recorded muscles.

The generation of motor outflow by the motor system also involves a concomitant activation of the vegetative system. Sympathetic outflow increases during motor preparation, in anticipation to metabolic changes due to subsequent muscular activity. Accordingly, an increase in heart rate has been observed during imagined movements (Decety et al., 1993; Oishi et al., 1994). The control of respiration also seems to be part of the package of central commands generated by the motor system at the time of preparation to action. Accordingly, respiration rate is increased during imagination of exercise, in proportion to the imagined effort (Wuyam et al., 1995). This is also the case during mere observation of a runner on a treadmill: the respiration rate of the observer increases with the speed of the runner (Paccalin and Jeannerod, 2000).

\section{Basal Ganglia}

Basal ganglia are found to be activated during imagined actions. There are indications that execution and imagination engage different parts of the striatum (Gerardin et al., 2000). During execution, the putamen, which is part of a purely sensorimotor corticocortical loop, is activated. During imagination, activation involves the head of the caudate, which is part of a more cognitive loop.

\section{Cerebellum}

Activation of the cerebellum during covert actions is congruent with that of the corticospinal system, if one considers the close functional linkage of the two systems during motor execution. Indeed, cerebellar activation was clearly found in imagined action (Ryding et al., 1993), in perceptually based motor decisions (Parsons et al., 1995) and during action observation (Grafton et al., 1996). The involved area includes both the medial and the lateral parts of the cerebellum. However, areas in the ipsilateral cerebellar hemisphere that are activated during execution (in the anterior lobe) are much less activated during imagination
(Lotze et al., 1999). By contrast, imagined action and action observation activate more posterior areas.

\section{Premotor Cortex}

Activation of premotor cortex is one of the most conspicuous findings across all S-states (see Table 2). Decety et al. (1994) found a large activation of the dorsal and ventral parts of lateral area 6 during imagined hand movements (see also Stephan et al., 1995; Grafton et al., 1996; Gerardin et al., 2000). This is also true for perceptually based motor decisions (Parsons et al., 1995) and visual presentation of graspable objects (Chao and Martin, 2000). During observation of hand movements, the same areas, principally in the ventral area 6, are activated (Rizzolatti et al. 1996; Grafton et al., 1996; Decety et al., 1997; Iacoboni et al., 1999), with a somatotopic organization when actions involving different body parts are observed (Buccino et al., 2001). Lateral premotor cortex activation during covert actions overlaps with movement execution for what concerns dorsal area 6 (Gerardin et al., 2000; Rizzolatti et $a l ., 1996)$ and involves an equivalent number of activated pixels whether the action is a covert or an overt one (Roth et al., 1996; Lotze et al., 1999). Activation of ventral area 6 in the inferior frontal gyrus, however, which is so clearly found in covert actions, is less frequently mentioned during execution (see Binkofski et al., 1999).

The same degree of overlap between conditions of covert and overt actions exists for SMA. The general trend is that SMA activation during imagined movements and action observation is more rostral than during executed movements (e.g., Stephan et al., 1995; Grafton, 1996; Gerardin et al., 2000; Lotze et al., 1999), but that the active zones partially overlap during Sstates and during execution. The function of SMA, which acts as a parser for temporally segmenting the action and anticipating its successive steps, is thus retained during S-states.

\section{Associative Cortical Areas}

\section{Parietal Cortex}

Parietal areas caudal and ventral to the primary parietal cortex are consistently activated during Sstates. Areas in the inferior parietal lobule and in the intraparietal sulcus are activated during imagined grasping movements (Decety et al., 1994; Grafton et al., 1996), perceptually based decisions and prospective action judgements (Parsons et al., 1995; Johnson, 2000), action observation (Buccino et al., 2001; Grafton et al., 1996), and visual presentation of graspable objects (Chao and Martin, 2000). During execution, the same parietal areas are also largely involved (Faillenot et al., 1997; Binkofski et al., 1999). The area involved 
during covert hand actions tends to extend more caudally than during overt actions (Gerardin et al., 2000).

Posterior parietal cortex may be the site where action representations are stored and/or generated. Because it integrates abundant visual and somatosensory information, it appears well suited for encoding the technicalities of the action, like transforming object spatial coordinates from a retinocentric framework into an egocentric framework, or processing the constraints related to the objects. These aspects are represented in many different $\mathrm{S}$-states.

\section{Prefrontal Cortex}

Prefrontal granular cortex is activated in most Sstates. Activation usually involves the dorsolateral part (areas 9 and 46), the orbitofrontal zone (areas 10 and 11), the cingular gyrus, and a ventral and caudal zone (areas 44-45, see Iacoboni et al., 1999) in continuity with the agranular zone of ventral area 6 . Dorsolateral prefrontal cortex is also notoriously activated during preparation states, when a decision must be taken about which finger to move or about when to start a movement (Frith et al., 1991). Prefrontal activation, which intervenes during S-states before an overt action starts, is far less marked during action execution.

\section{The Problem of Inhibition of Execution}

The simulation theory is faced with a difficult problem: how come that covert actions, in spite of activation of the motor system, do not result in muscular activity and overt movements. There are two possible explanations for this absence of motor output. The first one is that motor activation during S-states is subliminal, and therefore, insufficient to fire spinal motoneurons. The other, complementary one, postulates that motor output would be blocked before it reaches the motoneuron level, by an inhibitory mechanism generated in parallel to the motor activation. The simple fact that motor cortex remains activated during S-states excludes an inhibitory role of corticocortical connections. To account for the data, the inhibitory mechanism must therefore operate downstream to motor cortex, for example by blocking the descending corticospinal volleys at the spinal cord or brainstem level.

Data on spinal reflexes during S-states suggest such a possibility. Bonnet et al. (1997) found increased spinal reflexes (predominantly T-reflexes) during a mentally simulated isometric foot pressure, whereas Oishi et al. (1994) found decreased lower limb H-reflexes in elite athletes. Hashimoto and Rothwell (1999) found no significant change in upper limb H-reflexes during simulated wrist movements. Finally, Baldissera et al. (2001) found changes in upper limb H-reflexes during observation of finger flexion or extension. However, the pattern of activation appeared to be reverted with re- spect to that observed during imagined action, flexor motoneurons being facilitated during extension and vice versa. What remains from these conflicting results is that motoneuron excitability is affected during action simulation. Different testing conditions (e.g., lower limbs vs upper limbs, trained athletes vs normal people) may account for different amplitudes and directions of these changes. A tentative hypothesis could be that a dual mechanism operates at the spinal level: a subthreshold preparation to move by the increased corticospinal tract activity, and a parallel suppression of overt movement by inhibitory influences. A similar explanation was put forward in the monkey by Prut and Fetz (1999).

\section{EFFECTS OF BRAIN LESIONS ON S-STATES}

The theory predicts that lesions affecting the motor system should impair the expression of all S-states, but should leave intact their content. By contrast, lesions affecting structures located ahead of motor system should specifically affect the ability to produce a given S-state. Available data in the literature, although still incomplete, tend to converge in the expected direction.

\section{Lesions of the Motor System}

Both Decety and Boisson (1990) and Sirigu et al. (1995) reported that patients with hemiplegia following a corticospinal lesion were still able to generate imagined movements with their affected limb. When tested with the mental reciprocal task described above, Sirigu et al.'s patient showed the same regularities with both her normal and her affected hand. In these studies, the only difference between the mental performance of the two hands was that the affected hand was slower than the normal one. This difference was even not noticed in Johnson's (2000) hemiplegic patients tested in a perceptually induced motor decision. There are no comparable data available for lesions limited to premotor cortex or SMA. It is likely that this type of lesion should be more deleterious to imagined sequential movements than pure primary motor cortex lesions.

Patients with dysfunction of the basal ganglia (Parkinson's disease) also show deficits in covert actions. Patients with akinesia more severe on one side were still able to generate the motor image of a sequential finger task, although their performance was asymmetrical, with the worse affected hand slower than the other one (Dominey et al., 1995). A PET study of motor imagery involving the akinetic hand in such patients showed a lack of activation of primary motor cortex and cerebellum, with normal activation of SMA and parietal cortex (Thobois et al., 2000). 


\section{Lesions Upstream to the Motor System}

The effects of lesions located upstream with respect to the motor system are perhaps more interesting to consider, as they should produce different forms of disruptions of S-states according to the type or the location of the lesion.

\section{Posterior Parietal Cortex}

Disruption of motor representations has been reported following lesions of posterior parietal cortex. A patient with a unilateral parietal lesion was unable to mentally perform the reciprocal tapping task, using her contralateral hand. This impossibility contrasted with the fact that she performed normally with that hand when the task was overtly executed (Sirigu et al., 1996). Patients with posterior parietal lesions often present difficulties in tasks which require representing an action. Such patients cannot recognize pantomimed actions; they may be unable themselves to pantomime actions involving an object or a tool; they fail to recognize their own actions from those performed by other people (Sirigu et al., 1999). These impairments, which are part of the apraxia syndrome, clearly correspond to a lack of representation and recognition of action.

\section{Prefrontal Cortex}

Lesions affecting the prefrontal cortex also (and not surprisingly) alter the functioning of the simulation network. A critical example of this alteration is observed in patients with orbitofrontal lesions (Shallice et al., 1989). These patients tend to compulsively imitate gestures or even complex actions performed in front of them by another agent and cannot refrain from using graspable objects when presented to them. It would be interesting to know how such patients would behave during imagined actions. It is likely that they would be unable to generate motor imagery without immediately transferring it into motor output. A case with an opposite behavior was described in a patient with a hysterical paralysis of the left side of the body (Marshall et al., 1997). Although a normal activation (mapped with PET) of the left sensorimotor cortex was observed during movements of the right "good" leg, no such activation was observed on the right side during unsuccessful attempts to move the left "bad" leg. Instead, the right anterior cingulate and orbitofrontal cortices were significantly activated. This result suggests that these prefrontal areas exerted a state-dependent inhibition on the motor system when the intention to move the left leg was formed. It can be predicted that this patient should not be able to experience motor imagery with her affected leg, but that she should not have difficulty generating other types of motor images involving her other limbs. This remains to be tested.
The role of prefrontal cortex during S-states would be twofold. First, the orbitofrontal and cingular areas would exert an inhibitory influence on areas involved in S-states, its role being to select the appropriate network by either slowing down or releasing the activity of these areas according to the S-state in which the subject is engaged. The above pathological cases tend to support this view. This selective inhibition exerted by prefrontal cortex should not be confounded with the more global descending inhibition of motor commands already described at the spinal level. Second, dorsolateral prefrontal cortex, in conjunction with the basal ganglia, could be involved in short term information storage for anticipating the action goal and simulating the action to its completion.

\section{Psychotic States}

The simulation theory has been recently used as a possible framework for integrating social cognition to the neural substrate and for understanding the profound alterations of social behavior expressed by psychotic patients. When two agents socially interact with one another, representations are activated in their respective brains: each agent generates representations for his own (overt or covert) actions, and simultaneously simulates actions he observes from the other agent. In normal conditions, the existence of non-overlapping parts in the respectively activated networks allows each agent to discriminate what belongs to him from what belongs to the other. This process would thus be the basis for correctly attributing a representation (or the corresponding action) to the proper agent or, in other words, for answering the question of "Who" is the author of an action (Georgieff and Jeannerod, 1998).

This conception allows making hypotheses about the nature of the dysfunction responsible for misattribution of actions by schizophrenic patients. Changes in the pattern of cortical connectivity could alter the shape of the networks corresponding to different representations, or the relative intensity of activation in the areas composing these networks. In verbal hallucinations, for example, activity in primary temporal cortex is abnormally increased, which makes the patient feel that his voices originate from outside (Dierks et al., 2000). Similarly, in delusion of influence, posterior parietal activation is abnormally high, hence the experience of alien control (Spence et al., 1997). Prefrontal cortex is one of the possible origins of this perturbed activation during S-states in psychotic patients (Frith et al., 1995).

\section{CONCLUSION: THE ROLE OF SIMULATION IN MOTOR COGNITION}

The above pattern of results on the mechanisms of covert action corresponds to the central stages of action 
organization, uncontaminated by the effects of execution. As such, it represents a possible framework for motor cognition.

First, because all aspects of action appear to be involved during S-states, it seems a logical consequence of this rehearsal of the corresponding brain structures, and specifically the motor structures, that the subsequent execution will be facilitated. The presence of activity in the motor system during S-states would put the action representation in a true motor format, so that it would be regarded by the motor system as a real action. This facilitation would explain various forms of training (e.g., mental training) and learning (e.g., observational learning) which occur during S-states (see Pascual-Leone et al., 1995). In addition, imitation would be based on directly matching the observed action onto an internal simulation of that action (Iacoboni et al., 1999).

Second, activation of the motor cortex and of the descending motor pathway seems to fulfill several critical functions. First, this activation contributes to generating corollary signals that propagate upstream to parietal and premotor cortex. This mechanism would allow evaluation of the potential consequences of the future action (see Wolpert et al., 1995, for description of a control model which accounts for this function). It could also provide the subject with information for consciously monitoring his S-states and realizing that he is the agent of this covert activity, in spite of absence of overt behavior.

\section{REFERENCES}

Baldissera, F., Cavallari, P., Craighero, L., and Fadiga, L. 2001. Modulation of spinal excitability during observation of hand action in humans. Eur. J. Neurosci. 13: 190-194.

Binkofski, F., Buccino, G., Posse, S., Seitz, R. J., Rizzolatti, G., and Freund, H. J. 1999. A fronto-parietal circuit for object manipulation in man. Eur. J. Neurosci. 11: 3276-3286.

Bonnet, M., Decety, J., Requin, J., and Jeannerod, M. 1997. Mental simulation of an action modulates the excitability of spinal reflex pathways in man. Cogn. Brain Res. 5: 221-228.

Buccino, G., Binkofski, F., Fink, G. R., Fadiga, L., Fogassi, L., Gallese, V., Seitz, R. J., Zilles, K., Rizzolatti, G., and Freund, H. J. 2001. Action observation activates premotor and parietal areas in a somatotopic manner: An fMRI study. Eur. J. Neurosci. 13: 400404.

Chao, L. L., and Martin, A. 2000. Representation of manipulable man-made objects in the dorsal stream. NeuroImage 12: 478-494.

Decety, J., and Boisson, D. 1990. Effect of brain and spinal cord injuries on motor imagery. Eur. Arch. Psychiatry Clin. Neurosci. 240: $39-43$.

Decety, J., Jeannerod, M., and Prablanc, C. 1989. The timing of mentally represented actions. Behav. Brain Res. 34: 35-42.

Decety, J., Jeannerod, M., Durozard, D., and Baverel, G. 1993. Central activation of autonomic effectors during mental simulation of motor actions. J. Physiol. 461: 549-563.

Decety, J., Perani, D., Jeannerod, M., Bettinardi, V., Tadary, B., Woods, R., Mazziotta, J. C., and Fazio, F. 1994. Mapping motor representations with PET. Nature 371: 600-602.
Decety, J., Grezes, J., Costes, N., Perani, D., Jeannerod, M., Procyk, E., Grassi, F., and Fazio, F. 1997. Brain activity during observation of action. Influence of action content and subject's strategy. Brain 120: 1763-1777.

Dierks, T., Linden, D. E. J., Jandl, M., Formisano, E., Goebel, R., Lanferman, H., and Singer, W. 1999. Activation of the Heschl's gyrus during auditory hallucinations. Neuron 22: 615-621.

Dominey, P., Decety, J., Broussolle, E., Chazot, G., and Jeannerod, M. 1995. Motor imagery of a lateralized sequential task is asymmetrically slowed in hemi-Parkinson patients. Neuropsychologia 33: 727-741.

Fadiga, L., Fogassi, L., Pavesi, G., and Rizzolatti, G. 1995. Motor facilitation during action observation. A magnetic stimulation study. J. Neurophysiol. 73: 2608-2611.

Fadiga, L., Buccino, G., Craighero, L., Fogassi, L., Gallese, V., and Pavesi, G. 1999. Corticospinal excitability is specifically modulated by motor imagery: A magnetic stimulation study. Neuropsychologia 37: 147-158.

Faillenot, I., Toni, I., Decety, J., Gregoire, M. C., and Jeannerod, M. 1997. Visual pathways for object-oriented action and object recognition: Functional anatomy with PET. Cereb. Cortex 7: 77-85.

Frak, V. G., Paulignan, Y., and Jeannerod, M. 2001. Orientation of the opposition axis in mentally simulated grasping. Exp. Brain Res. 136: 120-127.

Frith, C. D., Friston, K., Liddle, P. F., and Frackowiak, R. S. J. 1991. Willed action and the prefrontal cortex in man: A study with PET. Proc. R. Soc. London B Biol. Sci. 244: 241-246.

Frith, C. D., Friston, K., Herold, S., Silbersweig, P., Fletcher, P., Cahill, C., Frackowiak, R. S. J., and Liddle, P. F. 1995. Regional brain activity in chronic schizophrenic patients during the performance of a verbal fluency task. Br. J. Psychiatry 167: 343-349.

Gallese, V., and Goldman, A. 1998. Mirror neurons and the simulation theory of mind reading. Trends Cogn. Sci. 2: 493-501.

Georgieff, N., and Jeannerod, M. 1998. Beyond consciousness of external reality: A "Who" system for consciousness of action and self-consciousness. Conscious. Cogn. 7: 465-472.

Gerardin, E., Sirigu, A., Lehéricy, S., Poline, J-B., Gaymard, B., Marsault, C., Agid, Y., and Le Bihan, D. 2000. Partially overlapping neural networks for real and imagined hand movements. Cereb. Cortex 10: 1093-1104.

Grafton, S. T., Arbib, M. A., Fadiga, L., and Rizzolatti, G. 1996. Localization of grasp representations in humans by positron emission tomography. 2. Observation compared with imagination. Exp. Brain Res. 112: 103-111.

Hari, R., Forss, N., Avikainen, S., Kirveskari, E., Salenius, S., and Rizzolatti, G. 1998. Activation of human primary motor cortex during action observation: A neuromagnetic study. Proc. Natl. Acad. Sci. USA 95: 15061-15065.

Hashimoto, R., and Rothwell, J. C. 1999. Dynamic changes in corticospinal excitability during motor imagery. Exp. Brain Res. 125: $75-81$.

Iacoboni, M., Woods, R. P., Brass, M., Bekkering, H., Mazziotta, J. C., and Rizzolatti, G. 1999. Cortical mechanisms of human imitation. Science 286: 2526-2528.

Jeannerod, M. 1994. The representing brain. Neural correlates of motor intention and imagery. Behav. Brain Sci. 17: 187-245.

Jeannerod, M. 1997. The Cognitive Neuroscience of Action. Blackwell, Oxford.

Johnson, 2000. Imagining the impossible: Intact motor imagery in hemiplegia. NeuroReport 11: 729-732.

Lotze, M., Montoya, P., Erb, M., Hülsmann, E., Flor, H., Klose, U., Birbaumer, N., and Grodd, W. 1999. Activation of cortical and cerebellar motor areas during executed and imagined hand movements: An fMRI study. J. Cogn. Neurosci. 11: 491-501. 
Marshall, J. C., Halligan, P. W., Fink, G. R., Wade, D. T., and Frackowiak, R. S. J. 1997. The functional anatomy of a hysterical paralysis. Cognition 64: B1-B8.

Oishi, K., Kimura, M., Yasukawa, M., Yoneda, T., and Maeshima, T. 1994. Amplitude reduction of H-reflex during mental movement simulation in elite athletes. Behav. Brain Res. 62: 55-61.

Paccalin, C., and Jeannerod, M. 2000. Changes in breathing during observation of effortful actions. Brain Res. 862: 194-200.

Parsons, L. M., Fox, P. T., Downs, J. H., Glass, T., Hirsch, T. B., Martin, C. C., Jerabek, P. A., and Lancaster, J. L. 1995. Use of implicit motor imagery for visual shape discrimination as revealed by PET. Nature 375: 54-58.

Pascual-Leone, A., Dang, N., Cohen, L. G., Brasil-Neto, J., Cammarota, A., and Hallett, M. 1995. Modulation of motor responses evoked by transcranial magnetic stimulation during the acquisition of new fine motor skills. J. Neurophysiol. 74: 1037-1045.

Perani, D., Cappa, S. F., Bettinardi, V., Bressi, S., Gorno-Tempini, M., Matarrese, M., and Fazio, F. 1995. Different neural systems for the recognition of animals and man-made tools. NeuroReport 6: 1637-1641.

Porro, C. A., Francescato, M. P., Cettolo, V., Diamond, M. E., Baraldi, P., Zuiani, C., Bazzochi, M., and di Prampero, P. E. 1996. Primary motor and sensory cortex activation during motor performance and motor imagery: A functional magnetic resonance study. J. Neurosci. 16: 7688-7698.

Prut, Y., and Fetz, E. E. 1999. Primate spinal interneurons show premovement instructed delay activity. Nature 401: 590-594.

Rizzolatti, G., Fadiga, L., Matelli, M., Bettinardi, V., Paulesu, E., Perani, D., and Fazio, F. 1996. Localization of grasp representations in humans by PET. 1. Observation versus execution. Exp. Brain Res. 111: 246-252.

Roth, M., Decety, J., Raybaudi, M., Massarelli, R., Delon-Martin, C., Segebarth, C., Morand, S., Gemignani, A., Décorps, M., and Jeannerod, M. 1996. Possible involvement of primary motor cortex in mentally simulated movement. A functional magnetic resonance imaging study. NeuroReport 7: 1280-1284.
Ryding, E., Decety, J., Sjolhom, H., Stenberg, G., and Ingvar, H. 1993. Motor imagery activates the cerebellum regionally. A SPECT rCBF study with ${ }^{99 \mathrm{~m}}$ Tc-HMPAO. Cogn. Brain Res. 1: $94-$ 99.

Shallice, T., Burgess, P. W., Schon, F., and Baxter, D. M. (1989) The origins of utilization behavior. Brain 112: 1587-1592.

Sirigu, A., Cohen, L., Duhamel, J.-R., Pillon, B., Dubois, B., Agid, Y., and Pierrot-Deseiligny, C. 1995. Congruent unilateral impairments for real and imagined hand movements. NeuroReport 6: 997-1001.

Sirigu, A., Duhamel, J.-R., Cohen, L., Pillon, B., Dubois, B., and Agid, Y. 1996. The mental representation of hand movements after parietal cortex damage. Science 273: 1564-1568.

Sirigu, A., Daprati, E., Pradat-Diehl, P., Franck, N., and Jeannerod, M. 1999. Perception of self-generated movement following left parietal lesion. Brain 122: 1867-1874.

Spence, S. A., Brooks, D. J., Hirsch, S. R., Liddle, P. F., Meehan, J., and Grasby, P. M. 1997. A PET study of voluntary movements in schizophrenic patients experiencing passivity phenomena (delusions of alien control). Brain 120: 1997-2011.

Stephan, K. M., Fink, G. R., Passingham, R. E., Silbersweig, D., Ceballos-Baumann, A. O., Frith, C. D., and Frackowiak, R. S. J. 1995. Functional anatomy of the mental representation of upper extremity movements in healthy subjects. J. Neurophysiol. 73: 373-386.

Thobois, S., Dominey, P. F., Decety, J., Pollack., Grégoire, M. C., Le Bars, D., and Broussolle, E. 2000. Motor imagery in normal subjects and in asymmetrical Parkinson's disease. A PET study. Neurology 55: 996-1002.

Wolpert, D. M., Ghahramani, Z., and Jordan, M. I. 1995. An internal model for sensorimotor integration. Science 269: 1880-1882.

Wuyam, B., Moosavi, S. H., Decety, J., Adams, L., Lansing, R. W., and Guz, A. 1995. Imagination of dynamic exercise produced ventilatory responses which were more apparent in competitive sportsmen. J. Physiol. 482: 713-724. 